\title{
Patient's occupation, electric \& head trauma in a cohort of 88 multiple system atrophy patients compared with the general population: a hypothesis stimulating pilot study
}

\begin{abstract}
Introduction: Multiple Systematic Atrophy (MSA) whose incidences virtually doubled within a decade, coinciding with major rises in total neurological mortality in the developed world. Aetiology of neurological diseases is linked to various 'Possible Occupations Linked' (POL) to neurological disease- Electronics and IT; Engineering, Chemicals, Solvents. Two inconsistent findings-electric shock and head injury have been reported by many MSA patients. This pilot study analyses differences between MSA patients and general population in regard to occupation and incidence of electric shock and head injury.
\end{abstract}

Methodology: Two-year cohort of MSA patients attending support groups completed a one page self-administered questionnaire. It explored age, sex, occupation and electric shock and head injury, contrasted with estimates in the General Public, occupations were determined from ONS data, from which odds ratios of patients and general population were calculated

Results: Of 88 patients, $34 \%$ were aged under $60 ; 56 \%$ occupations were POL compared to $24 \%$ in regional population; one in 1.52 MSA patients reported head injury and 1:3.26 electric shock. This yielded odd ratios of patients to general population of 1:91.4 and 1:589.9 respectively. Patents with Other occupations had significantly more trauma than POL patients.

Discussion: Despite the limits of the study $34 \%$ of the cohort were relatively young for neurological disease, double the 'possible occupational links' to neurological disease than the general population and substantially higher trauma incidence. This pilot study indicates the need for a more focused analysis of possible tripping contributory factors in the aetiology of MSA.

Keywords: MSA, occupation, head injury, electric shock
Volume 8 Issue 3- 2018

\section{Colin Pritchard, Anne Silk}

Faculty of Health \& Social Sciences, Bournemouth University, UK

Correspondence: Colin Pritchard, Faculty of Health \& Social Sciences, Bournemouth University, Royal London House, Christchurch Rd, Bournemouth BH!3LT, UK, Tel 02380766487 , Email cpritchard@bournemouth.ac.uk

Received: May II, 2018| Published: June 14, 2018
Abbreviations: MSA, multiple systematic atrophy; POL, possible occupations linked; MND, motor neurone disease; EON, early-onset-dementia; DLB, dementia with lewy bodies; PSP, progressive supranuclear palsy; CBD, cortico basal degeneration; PROM, patient related outcome measures; POL, possible occupational linked; EMF, electro magnetic field

\section{Introduction}

Setting the Scene: The Macro: Over the past 20years, across the Western world there is evidence of major increases in neurological morbidity, including significant rises in the dementias, Motor Neurone Disease (MND) and in early-onset-dementia. ${ }^{1-7}$ In a series of population-based international comparative studies, looking at total neurological mortality rates from 1997 and concluding in 2014, it was shown that neurological deaths in the 55-74age band and especially the over 75's, have far exceeded the increases in the countries' population in those age bands. For example in the UK, the elderly population, the over 75 's increased by $26 \%$ but neurological death rates rose by $168 \%$ since 1989-91 up to 2013. Whilst the USA elderly population rose $49 \%$ but neurological deaths rose five-fold. ${ }^{8-10}$ Whilst these and other studies indicated that the dementias were probably starting a decade earlier ${ }^{6-10}$. Coinciding with these increases, Asian countries which compared to Western countries have always had lower neurological morbidity, have recently been reporting notable rises over the past two decades. ${ }^{5,11,12}$

Some have argued that rises in neurological morbidity are due to the Gompertzian hypothesis i.e. people are now living longer to develop conditions that previously they had not lived long enough to do so, ${ }^{13-15}$ or perhaps better diagnosis ${ }^{16}$ but substantial rises in a range of neurological conditions have been noted, such as MND, PSP, MSA, Parkinson's etc, ${ }^{1-11}$ which were not primarily related to longevity and have mirrored rises in the majority of the 21 Western countries and in Asia and Latin America. ${ }^{6,10-12,17-23}$ These increases are exemplified from studies of Early-Onset-Dementia (EON) whilst in Britain there has been the need for a new charity to deal with the problem, Young Dementia UK, many of whose clients are under 50. Whilst in the longestablished charity, the Parkinson's Disease Society, now has a Young Persons section, as more and more patients are under 40 . 
The Micro: Multiple System Atrophy (MSA): The focus of this study is upon a relatively rare condition, Multiple System Atrophy (MSA) which was once thought to be a variation of Parkinson's Disease and had previously been described as the Shy-Drager syndrome but is now known to be a separate disease entity from Parkinson's. ${ }^{23-30}$. Typically in response to patient need there are self-help generated NGO's and there are now 37 MSA Trust support groups around the UK, reflecting the changing pattern of MSA and the Trust is celebrating its $20^{\text {th }}$ anniversary.

In 2001 the European Study Group on 'atypical Parkinsonism' reported that the prevalence of MSA was between 4 and 5 per 100,000 people. ${ }^{23}$ However, other studies have highlighted changes in the widening understanding of Parkinson type illnesses. ${ }^{25-30}$ They stated that aside from idiopathic Parkinson syndrome, there are a number of other atypical Parkinsonian syndromes: Dementia with Lewy Bodies (DLB), Progressive Supranuclear Palsy (PSP), Cortico basal Degeneration (CBD) as well as Multiple System Atrophy.However, whilst DLB is relatively a common disease, a prevalence of $0.4 \%$ (400 cases per 100,000 persons) the later studies found that MSA and PSP have a prevalence of between 5 to 10 per 100,000 persons respectively, ${ }^{23-26,29,30}$ virtually doubling the estimates of MSA a decade earlier ${ }^{23}$ which mirrors the growing number of MSA Trustsupport groups across the UK.

The extent of increases in MSA is seen when counting Medline papers on MSA (including those specifically mentioning Shy-Drager syndrome). From the first paper in 1977 it took until 1987 to have 100papers but between January 2017 and January 2018 there were 145 specific MSA studies, strongly indicating rises in MSA morbidity and from countries around the world not just amongst Western countries. ${ }^{3,11,24-31}$ Inevitably there has been speculation as to the presumed multiple environmental and epigenetic aetiology of MSA. Whilst some studies have found little statistical association between occupations, especially pesticides and solvents with neurological disease, ${ }^{31,32}$ others have found a range of possible environmental influences, including solvents, pesticides, heavy metals and air pollution 31-36. All of which of course are linked to various occupations. $^{31,33-43}$

One problem with these relatively rare or uncommon disorders is to hear from the patient's perspective, reflecting the aim of England's Chief Medical Officer, for more Patient Related Outcome Measures (PROM). The value of listening to the patient's 'agenda' was found in the post-operative outcomes of former sub-arachnoid haemorrhage patients, who identified treatable issues that previously the professionals had missed. ${ }^{44}$ In informal meetings with MSA patients, many mentioned either electric shock, head injury or both and they wondered whether this might be related to the development of their condition. When the patients raised this with various professionals it was generally dismissed as having no relevance.

So far we have only commented upon possible interactive environmental factors yet self-evidently many authors point towards genetic and epigenetic factors under-lying the pathology of many neurological diseases ${ }^{45-49}$ However, this project focuses specifically upon on MSA patients' occupational backgrounds and any reported life style traumatic events, following the many patients who had previously volunteered such information. Exploring the literature on such events, a link between neurological disease and electric shock was described by Dureux in $1958^{43}$ but the evidence on electric shock and neurological disorders is inconsistent, some report either no association or the linkage is very weak ${ }^{34,47}$ whilst others have found a significant connection. ${ }^{37,38,50-55} \mathrm{~A}$ study of particular possible relevance strongly indicated that there appeared to be a degree of delayed neurological reaction, from months to many years, before symptoms appeared. ${ }^{56}$

In a systematic review by Campbell \& Dini they make a very strong case, arguing that occupational injuries from electric shock and arc flash events, are well known in the health and safety world, but do not appear to have a high priority in the neurological field ${ }^{43}$ This reflects national studies in Europe and Switzerland, which recognised that some occupations had a substantially higher risk of electric shocks than others..$^{50-55}$ Whilst studies from Scandinavia using their national register found an expanding Electromagnetic Field (EMF) in the human environment and rises in neurological disease. ${ }^{33,52-54}$ In regard to head injury, occupational and body contact sports are associated with subsequent neurological disease but again a degree of ambiguity in respect to severity and age of occurrence. ${ }^{57-61}$ A study that used the Finnish National Registry over a thirty year period concluded that head injury was associated with the dementia but the evidence was less clear specifically in regard to MND and Parkinson's Disease. ${ }^{60}$

It may be therefore, that after 'listening' to MSA patients, it might be possible to shed a little light on what is inevitably a highly complex problem. This hypothesis study is in effect pilot study taking a patient centred approach to explore the background and occupation of confirmed MSA patients asking them about their experiences. Because of the frequency in which head injury and electric shock had been mentioned it was decided to test this in a more uniform way. In conjunction with the patients attending MSA Trustsupport groups a simple one page confidential, totally anonymous self-administered questionnaire was designed, to explore their occupation and whether they had experienced a head injury or electric shock as an individual.

There are two simple null working hypotheses. That there will be no statistically significant differences between a cohort of people with confirmed MSA and the general public in regard to:

i. occupational backgrounds, and,

ii. The incidence of electric shock/head injury.

\section{Method}

Through the kind offices of the MSA Trust we were given access to audit a two year cohort of confirmed MSA patients attending MSA Trust support groups in the South East of England, who were invited to voluntarily complete a page-page self-administered questionnaire. We explored their occupational background and any frequency of electric shock and head injury in their adult life-times. The questionnaire was voluntary, confidential and anonymousand neither the support group nor any individuals can be identified. To preserve total anonymity and attribution, the questionnaires were destroyed after extracting the data. The questionnaire covered their, age, gender, occupation, and whether as adults, they had received an electric shock or had a head injury. We could not ask about possible family incidence of neurological disease as this had been thought too sensitive. So we have no indication as to possible other family members who might have had a neurological condition.

It is readily acknowledged that we could not obtain substantiated information on the degree and level or extent of the two 'traumatic' event from other sources. However, determining the relative frequency of such events in the general population compared to the MSA group 
appears to be worth exploring in this hypothesis stimulating pilot study to explore whether there would be merit in expanding more detailed research in regard to occupations and the traumatic events.

\section{Macro context}

To place the MSA patient's background and experience of occupation and the two traumatic events, these were to be compared with the estimated frequency in the general population. We sought to determine patterns of occupation, incidence of head injury and electric shock in the general population to see if there were any proportional differences between the MSA people and the general population.

In regard to Occupation we focused upon the types of employment that research has shown to more likely to lead to electric shock or/ and head injury and the development of neurological disease. ${ }^{33,34,37-60}$ These occupations covered four broad areas:- engineering, chemicals, solvents and IT and Electronics. ${ }^{31,32-43}$ Which we schematically describe as 'possible occupational linked' (POL) to neurological disease. Respondents not in the POL occupations were then grouped as 'Other' occupations. Based upon current ONS data it was possible to extract data of the general population's POL and Other occupations in the South East region of England, ${ }^{62}$ to contrast the occupational background found amongst the MSA cohort.

In respect to the incidence of Electric Shock, we could not find any data on the incidence of Electric Shocks in the UK so drew upon recent estimates from the USA. ${ }^{43}$ Based upon the USA general male population 20-65years, to allow for occupation bias, yielded an estimate of 1 in 3,428 people. A study from France however focusing on electric shocks in workers in the 'electronics' field ranged from $52-100$ per 100,000 workers or as between as 1 in 1000 or one in 1,923 people, highlighting the relative risks in different occupation. ${ }^{55}$ To avoid over-estimating electric shock factors we use 'lower' ratio of 1:1923 ratio against which to compare any electric shocks in the MSA cohort.

As with Electric shocks we could find no authoritative incidence of Head Injury in the UK. However, a study using Swedish data on head injuries who reported that $3.4 \%$ of all Sweden's A\&E admissions were related primarily to a head injury. ${ }^{63}$ Using this figure as a denominator, to estimate the possible head injury in the UK general public, we examined A\&E data for England to find that there were 5.5 million people with at least one over-night stay. ${ }^{63-66}$ Thus if $3.4 \%$ of English A\&E admissions were head injuries, as in Sweden, this gives us approximately 187,000 who had a head injury. Based upon the UK population aged 20-60 yields ratios of 1:139 people. The above general population ratios will be juxtaposed again incidence in the patient cohort

\section{Results}

There were 88 completed questionnaires, four were unreturned. Unfortunately six respondents did not include their occupation and eight missed filling in their age. In view of the relative paucity of studies of MSA patient's views, cases were not omitted if only two variables were missing and therefore included in the analysis of the results but missing data is ignored. However, only the positive reporting of one of the two traumas is considered to be an event. Hence the percentages of the trauma are based upon the total 88 MSA patients.

\section{Age \& gender}

Fifty-five( $63 \%$ ) of the cohort were males. Four patients(5\%) were aged 44 and under, a further twenty-three were under sixty (29\%) thus $34 \%$ of the cohort might be considered early to have a serious neurological disease, as symptoms had appeared some years earlier. Between the ages of 60 to 69 were a further 26(33\%) people. The $70-75$ year olds accounted for $22(28 \%)$ more people and five who were over the age of 80 . Thus the cohort age ranged from under thirty to 83 , with a mean of 61years. There appeared to be no statistically significant difference in age and gender in the cohort.

\section{Occupations}

The occupations of the general population related to the 4.217 million people employed in the region. There were 1.001 million people $(24 \%)$ people employed in agriculture, mining, manufacturing, construction electronic and IT industries, which was the closest match to the four 'possible occupational linked' (POL) to neurological disease. Although six MSA respondents did not include their jobs, the four main occupations of interest were 16 people in electronics and IT, followed by thirteen people in engineering, nine in chemicals and eight in solvents. Excluding respondents who did not report their occupations this means that 46 people $(56 \%)$ were engaged in POL, which was more than double the regional percentage. 'Other' employment of the remaining twenty-eight people came from a range of occupations, mainly sedentary.

\section{Head injury \& electrical shocks}

The lowest estimates of head injury in the general population was one in 139people. In respect to estimates of electric shocks in the general population the ratio was 1:1923. We report separately on each of the two traumatic events but 22 of the MSA patients reported having both an electric shock and a head injury- shown in brackets in the table. Fifty-eight of the eighty-eight MSA patients reported having a head injury $(66 \%)$, a ratio of $1: 1.52$ patients. In regard to electric shock there were 27 MSA patients (31\%) a ratio of 1:3.26, compared to the1@1932 in the general population. These findings yields odds ratios of MSA patients to the general population of one MSA person to 91.4 in the general population for head injury and one to 589 for electric shocks. Thus compared with the estimates in the general population of head injury and electric shocks, the MSA cohort far exceeded any rates that might have been expected (Table 1).

Remembering the missing data the following Table 2 shows the breakdown of traumatic events by age, sex and occupation. A possibly intriguing finding is the 'Other' occupations had proportionately more traumatic incidents. By comparing the traumatic' incidents of electric shock and head injury by POL versus Other occupations there was a significant link between trauma and more 'Other' occupation than MSA patients with POL occupations $\left(X^{2}=8.782 \mathrm{~d} / \mathrm{f} \mathrm{p}<0.02\right)$. Moreover when contrasting both traumas, numbers of injuries and no injuries, again significantly more Other occupations MSA patients more often had both traumas $\left(\mathrm{X}^{2}=8.97 \mathrm{p}<0.012\right)$. These two findings possibly suggests that the trauma events might have contributed to the development of the MSA condition, especially patients belonging to 'Other' occupations. Though of course, we know nothing about their family background. 
Table 1 Demographics male v female by age

\begin{tabular}{llll}
\hline Age $\mathbf{n = 8 0} \#$ & Male $\mathbf{N = 5 0}$ & Female $\mathbf{N = 3 0}$ & Total $\%$ \\
\hline Age $>44$ & 3 & I & $5 \%$ \\
$45-59$ & 12 & 11 & $29 \%$ \\
$60-69$ & 14 & 12 & $33 \%$ \\
$70+$ & 21 & 6 & $34 \%$ \\
Totals $\%$ & $63 \%$ & $37 \%$ & $100 \%$ \\
\hline
\end{tabular}

\# Missing data

Table 2 Comparing 'Other' and 'possible neuro linked occupations' (PNLO) incidence of electric shock and head injury by sex. Some patients had both head and eclectic shock injury (in brackets)

\begin{tabular}{|c|c|c|c|}
\hline $\begin{array}{l}\text { Category total } \\
\text { occupations } n=82\end{array}$ & $\begin{array}{l}\text { Electric } \\
\text { shock }\end{array}$ & $\begin{array}{l}\text { Head } \\
\text { injury }\end{array}$ & $\begin{array}{l}\text { No } \\
\text { injuries }\end{array}$ \\
\hline Other-Males $n=19$ & $8(7)$ & $15(7)$ & I \\
\hline Other-Females $n=17$ & $6(4)$ & $16(4)$ & 2 \\
\hline Total Other MSA & $14(1 \mid)-39 \%$ & $3 I(I I)-86 \%$ & $3-8 \%$ \\
\hline PNLO-Males n=34 & $12(11)$ & $2 I(I I)$ & II \\
\hline PNLO-Females $n=12$ & $I(I)$ & $7(1)$ & 4 \\
\hline Total PNLO MSA & I3(II)-28\% & $\begin{array}{l}27(12)- \\
61 \%\end{array}$ & $15-33 \%$ \\
\hline
\end{tabular}

\section{Discussion}

The key limit to the study is that we know nothing of the cohort's family/genetic background, as many authors point towards an epigenetic under-lying pathology. ${ }^{45-49}$ The other limit in the study is the problem of missing data, also the inability to more accurately identify the severity of head and electrical shock events although we have more detail on occupations from the POL regional categories. Also it is acknowledged that the ratios of head injuries and electric shocks in the general population are only estimates, but as $73 \%$ of the cohort reported a head injury and 39\% mentioned an electric shock, it is fair to assume the level of these incidents in the general population are above any chance artefact.

Also a number of the studies related to occupation noted the problem of having only small samples of MSA means there is a limitation to any meaningful statistical analysis. ${ }^{25-28,30,31,34}$ However, despite the limitations in this study we think it is the first to follow the 'patient's agenda' which includes their view of possible multiple aetiological factors. But we need to recognise that physiological observables have multiple interactive causes as studying them in isolation leads to inconsistent patterns of apparent causality when it is the simultaneous combination of other multiple factors. Thus this study indicates a possible interaction between MSA patient's occupation and traumatic events, all reflecting the likely epigenetic under-lying interaction as a multiple environmental factors come together to lead to the manifestation of MSA or other neurodegenerative disorders affect. The traumatic events might well be the tripping point in the development of MSA in possible occupationally and familybackground' vulnerable people?

A practical issue is that these results should remind us that 'health and safety' continues to be an important factor, especially related to people working in possible health affecting environments.
A worthwhile but worrying finding is that that $34 \%$ of these people with MSA were aged under sixty, indeed $8 \%$ were aged under fifty years old, thus a third of these MSA patients might be described as belonging to an early-onset-dementia group or certainly early severe neurological disease at a relatively young age. The authors have the benefits of being able to look back over more than 50 clinical years, to appreciate the enormous change in the number of neurological conditions. This occurred at a time of major increases in neurological morbidity and mortality, not only MSA but MND, PSP and throughout the wider world. ${ }^{1-13,18-20,31,32,36}$

Clearly there are changes and it would seem that there is an association with modern living and increases in neurological conditions at unprecedented rates. This is more than just the Gompertzian hypothesis, people living longer to develop disease they died too young to have in former time, ${ }^{14-17}$ nor is it likely to be just better diagnosis, rather the rapid change and possible interactions of levels of Electromagnetic field backgrounds, heavy metals, spin generating Reactive Oxygen Species, organophosphates and hormone disrupting chemicals in the human environment. ${ }^{21,31-33,35,36,38,40,47,54}$

Finally, despite the limitations of the study, we state with the greatest caution that it appears that a head injury and/ or an electric shock might possibly have contributed to the development of MSA as well as occupation and be the tripping point.This hypothesis stimulating pilot study suggeststhat there would be value in a more detailed subsequent exploration of these disproportionate traumatic and occupational factors that might contribute to the development of and increases in Multiple Systematic Atrophy.

\section{Acknowledgements}

None.

\section{External funding}

There was no external funding for the study.

\section{Conflict of interest}

The authors have no vested or conflict of interests in this study.

\section{References}

1. Saito R, Tada M, Toyoshima Y, et al. Loss of motor neurons innervating cervical muscles in patients with multiple system atrophy and dropped head. J Neuropathol Exp Neurol. 2018;77(4):317-324.

2. Zhang L, Cao B, Zou Y, et al. Causes of death in chinese patients with multiple system atrophy. Aging Dis. 2018;9(1):102-108.

3. Zhou X, Wang C, Chen Z, et al. Association of TNF- $\alpha$ rs 1799964 and IL$-1 \beta$ rs 16944 polymorphisms with multiple system atrophy in Chinese Han population. Int J Neurosci. 2018;128(8):761-764.

4. Bergen DC, Silberberg D. Nervous system disorders: a global epidemic. Arch Neurol. 2002;59(7):1194-1196.

5. Alonso A, Logroscino G, Jilick SS, et al. Incidence and lifetime risk of motor neurone disease in the United Kingdom: A population based study. Eur J Neurology. 2009;16(6):745-751.

6. Gordon PH, Artaud F, Aouba A, et al. Changing mortality for motor neuron disease in France (1968-2007): an age-period cohort analysis. Eur J Epidem. 2011;26(9):729-737.

7. Scialo C, Novi G, Bandettini D. Clinical epidemiology of ALS in liguria, Italy: an update of LIGALS register. Amyo Lat Scl Front Degen. 2016;11:1-8. 
8. Kasai M, Nakamura K, Meguro K. Alzheimer's disease in Japan and other countries: review of the epidemiological studies in the last 10 years. Brain Nerve. 2010;62(7):667-678.

9. Kelley BJ, Boeve BF, Josephs KA. Young-onset dementia: Demographic and aetiological characteristics of 235 patients. ArchNeurol. 2008; 65(11):1502-1508.

10. Panegyres PK, Chen HY. Early-onset Alzheimer's disease: A global cross-sectional analysis. Euro J Neurol. 2014; 21(9):1149-1154.

11. Pritchard C, Baldwin D, Mayers A. Changing patterns of adult [45-74years] neurological deaths in the major Western world countries 1979-1997. Public Health. 2004;118(4):268-283.

12. Pritchard C, Mayers A, Baldwin DS. Changing patterns of neurological mortality in the 10 major developed countries 1979-2010. Public Health. 2013;127(4):357-368.

13. Pritchard C, Rosenorn-Lanng E, Silk A, et al. International and USA population-based study comparing adult [55-74] neurological deaths with control cancer and circulatory disease deaths 1989-2014. Acta Neurol Scand. 2017;136(6):698-707.

14. Shahrizaila N, Sobue G, Kuwabara S, et al. Amyotrophic lateral sclerosis and motor neuron syndromes in Asia. J Neurol Neurosurg Psychiat. 2016;87(8):821-830.

15. Sulena, Gupta D, Sharma AK, et al. Clinical profile of dysphagia in patients with Parkinson's disease, progressive supranuclear. J Assoc Physicians India. 2017;65(8):32-37.

16. Chio A, Magnani C, Schiffer D. Gompertzian analysis of ALS mortality in Italy 1957-1987: Application to birth cohorts. Neuroepidemiology. 1995;14:269-277.

17. Easton DM. Gompertzian growth and decay: A powerful descriptive tool for neuroscience. Physiological behaviour. 2005;86(3):407-414.

18. Riggs JE, Schochet SS Jr. Rising mortality due to Parkinson' disease \& ALS: A manifestation of the competitive nature of human mortality. J Clin Epidemiol. 1998;45(9):1007-1012.

19. Goldacre MJ, Duncan M, Griffith M, et al. Trends in death certification for Multiple sclerosis, motor neurone disease, Parkinson's disease and epilepsy in English populations 1979-2006. J Neurol. 2010;257(5):706-715.

20. James BD, Leurgans SE, Hbert LE, et al. Contribution of Alzheimer disease to mortality in the United States. Neurology. 2014;82(12):1045-1050.

21. Moura MC, Casulari LA, Carvalho Garbi MR. Ethinc and demographic incidence of amyotrophic lateral sclerosis (ALS) in Brazil: A population based study. Amyo Lat Scler Front Degen. 2016;17(3-4):275-281.

22. Sanchez AM, Scharovsky D, RomanoLM. Incidence of early-onset dementia in Mar Del Plata. Neurologica. 2017;30(2):72-80.

23. Kim JM, Jeong HJ, Bae YJ, et al. Loss of substantia nigra hyperintensity on 7 Tesla MRI of Parkinson's disease, multiple system atrophy, and progressive supranuclear palsy. Parkinsonism Relat Disord. 2016;26:47-54.

24. Wang Y, Butros SR, Shuai X, et al. Different iron-deposition patterns of multiple system atrophy with predominant parkinsonism and idiopathetic Parkinson diseases demonstrated by phase-corrected susceptibility-weighted imaging. Am J Neuroradiol. 2012;33(2):266-273.

25. Wang N, Yang $\mathrm{H}$, Li C, et al. Using 'swallow-tail' sign and putamina hypo-intensity as biomarkers to distinguish multiple system atrophy from idiopathic Parkinson's disease: A susceptibility-weighted imaging study. Eur Radiol. 2017;27(8):3174-3180.

26. Vanacore N, Bonifati V, Fabbrini G, et al. European Study Group on Atypical Parkinsonism (ESGAP). Epidemiology of multiple system atrophy. ESGAP Consortium. European Study Group on Atypical Parkinsonisms.

\section{Neurol Sci. 2001;22(1):97-99.}

27. Morris HR1, Vaughan JR, Datta SR, et al. Multiple system atrophy/progressive supranuclear palsy: alpha-Synuclein, synphilin, tau, and APOE. Neurology. 2000;55(12):1918-1920.

28. Levin J, Kurz A, Arzberger T, et al. The differential diagnosis and treatment of atypical parkinsonism. Dtsch Arztebl Int. 2016;113(5):61-69.

29. Csencsits-Smith K, Suescun J, Li K, et al. Serum lymphocyte-associated cytokine concentrations change more rapidly over time in multiple system atrophy compared to parkinson disease. Neuroimmunomodulation. 2016;23(5-6):301-308

30. Brajkovic L, Kostic V, Sobic-Saranovic D, et al. The utility of FDG-PET in the differential diagnosis of parkinsonism. Neurol Res. 2017;39(8):675684 .

31. Vanacore N. Epidemiological evidence on multiple system atrophy. $J \mathrm{Neu}$ ral Transm. 2005;112(12):1605-1612.

32. Bjornsdottir A1, Gudmundsson G, Blondal H, et al. Incidence and prevalence of multiple system atrophy: a nationwide study in Iceland. $J$ NeurolNeurosurgPsychiat. 2013;84(2):136-140.

33. Chrysostome V, Tison F, Yekhlef F, et al. Epidemiology of multiple system atrophy: a prevalence and pilot risk factor study in Aquitaine, France. $\mathrm{Neu}$ roepidemiology. 2004;23(4):201-208.

34. Cho JW, Jeon BS, Jeong D, et al. Association between Parkinsonism and participation in agriculture in Korea. J Clin Neurol. 2008;4(1):23-28.

35. Chen CY, Hung HJ, Chang KH, et al. Long-term exposure to air pollution and the incidence of Parkinson's disease: A nested case-control study. PLoS One. 2017;12(8):e182834.

36. Brouwer M, Koeman T, van den Brandt PA, et al. Occupational exposures and Parkinson's disease mortality in a prospective dutch cohort. Occup Environ Med. 2015;72(6):448-455.

37. Fischer H, Kheifets L, HussA, et al. Occupational exposure to electricshocks and magnetic fields and amyotrophic lateral sclerosis in Sweden. Epidemiology. 2015;26(6):137-146.

1.

38. Goldman SM, Quinlan PJ, Ross GW, et al. Solvent exposures and Parkinson disease risk in twins. Ann Neurol. 2012;71(6):776-784.

39. Han YH, Lee JH, Kang BM, et al. Topographical differences of brain iron deposition between progressive supranuclear palsy and parkinsonian variant multiple system atrophy. J Neurol Sci. 2013;325(1-2):29-35.

40. Huss A, Vermeulen R, Bowman JD, et al. Electricshocks at work in Europe: development of a job exposure matrix. Occup Environ Med. 2013;70(4):261-267.

41. Stampfer MJ. Welding occupations and mortality from Parkinson's disease and other neurodegenerative diseases among United States men, 1985 1999. J Occup Environ Hyg. 2009;6(5):267-272.

42. Teschke K, Marion SA, Tsui JK, et al. Parkinson's disease and occupation: differences in associations by case identification method suggest referral bias. Am J Ind Med. 2014;57(2):163-171.

43. Valdés EG, Andel R, Sieurin J, et al. Occupational complexity and risk of Parkinson's disease. PLoS One. 2014;8(9):9-18:

44. Beard JD, Steege AL, Ju J, et al. Mortality from amyotrophic lateral sclerosis and parkinson's disease among different occupation groups - United States, 1985-2011. Morb Mortal Wkly Rep. 2017;66(22):718-722.

45. Huss A, Spoerri A, Egger M, et al. Swiss National Cohort. Occupational exposure to magnetic fields and electricshocks and risk of ALS: the Swiss National Cohort. AmyoLatlScler Front Degener. 2015;16(1-2):80-85. 
46. Campbell RB, Dini DA. Occupational Injuries from Electrical Shock and Arc Flash Events. New York: Springer; 2016.

47. Pritchard C, Lindsay K, Cox M. et al. Re-evaluating the National Sub arachnoid Haemorrhage study (2006) from a Patient-Related-Outcome-Measure perspective: comparing fiscal outcomes of Treatment-as-Usual with an enhanced service. Brit J Neurosurg. 2011;25(3):376-383.

48. Nilsson C, Lndqvist LM, Nilsson K, et al. Age-related incidence and family history in frontotemporal dementia: data from the swedish dementia registry. Plos One. 2014;9(4):90-94.

49. Gangisetty D, Murugan S. Epigenetic modifications in neurological disease: Natural products as epigenetic modulators. Adv Neurol. 2016;12:1-25.

50. Sanyal J, Chakraborty DP, Sarkar B, et al. Environmental and familial risk factors of Parkinsons disease: case-control study. Can J Neurol Sci. 2010:37(5):637-642.

51. Nicolas G, Wallon D, Charbonnier C. Screen of dementia genes by whole-exome sequencing in early-onset Alzheimer disease. Eur J Hum Gentics. 2016;24(5);710-716.

52. Vidal JS, Vidailhet M, Derkinderen P, et al. Familial aggregation in atypical Parkinson's disease: a case control study in multiple system atrophy and progressive supranuclear palsy. J Neurol. 2010;257(8):1388-1393.

53. Van der Mark M, Vermeulen R, Nijssen PC, et al. Extremely low-frequency magnetic field exposure, electrical shocks and risk of Parkinson's disease. Int Arch Occup Environ Health. 2015;88(2):227-234.

54. Pedersen $\mathrm{C}$, Poulsen AH, Rod NH, et al. Occupational exposure to extremely low-frequency magnetic fields and risk for central nervous system disease: an update of a Danish cohort study among utility workers. Int Arch Occup Environ Health. 2017;90(7):619-628.

55. Johnansen C. Electromagnetic fields and health effects-epidemiological studies of cancer, diseases of the central nervous system and arrhythmia heart disease. Scand J Work Envion Health. 2004;30(Suppl 1);1-80.

56. Grell K1, Meersohn A, Schüz J, et al. Risk of neurological diseases among survivors of electric shocks: a nationwide cohort study, Denmark, 1968-
2008. Bioelectromagnetics. 2012;33(6):459-465.

57. Hallberg O. A trend modal Alzheimer disease. ADMET. 2015;3:281-286.

58. Vergara XP, Fischer HJ, Yost M, et al. Job exposure matrix for electric shock risks with their uncertainties. Int J Environ Res Public Health. 2015;12(4):3889-3902.

59. Berg JS, Morse MS. A Shocking Neurological Rarity. Practical Neurology. 2004;4:222-227.

60. van der Naalt J, Timmerman ME, de Koning ME, et al. Early predictors of outcome after mild traumatic brain injury (UPFRONT): an observational cohort study. Lancet Neurol. 2017;16(7):532-540.

61. Armon C, Nelson LM. Is headtrauma a risk factor for amyotrophic lateral sclerosis? An evidence based review. Amyotroph Lateral Scler. 2014;13(4):351-356

62. McKee AC, Daneshvar DH, Alvarez VE, et al. The neuropathology of sport. Acta Neuropathol. 2014;127(1):29-51.

63. Raj R, Kaprio J, Korja M, et al. Risk of hospitalization with neurodegenerative disease after moderate-to-severe traumatic brain injury in the working-age population: A retrospective cohort study using the Finnish national health registries. PLoS Med. 2017;14(7):e1002316.

64. Janssen PH, Mandrekar J, Mielke MM, et al. High school football and late-life risk of neurodegenerative syndromes, 1956-1970. Mayo Clin Proc. 2017;92(1):66-71

65. ONS. Number of people in employment in the South East of England aged 16 years and over, by type of industry: UK and non-UK nationals; 2016.

66. Andersson EH1, Björklund R, Emanuelson I, et al. Epidemiology of traumatic brain injury: a population based study in western Sweden. Acta Neurol Scand. 2003;107(4):256-259. 